Fecha de recepción: noviembre 2020

Fecha de aprobación: diciembre 2020

Fecha publicación: marzo 2021

\section{Articulación secuencial: la sintaxis gráfica}

Diego Agrimbau ${ }^{(1)}$

(1) Diego Agrimbau (Buenos Aires, 1975) ha realizado historietas desde principios de los 90's. Luego de varias experiencias como autoeditor, comenzó su carrera profesional como guionista en 2003. Desde entonces ha colaborado con editoriales europeas como Casterman, Albin Michel, L'Atalante, Saure, Aurea, Norma Editorial, Planeta DeAgostini, Ínsula y La Cúpula. También ha realizado trabajos para editoriales argentinas y latinoamericanas como Historieteca, Agua Negra, Loco Rabia, Belerofonte, VyR, Latinbooks, entre otras. En 2011 realizó una residencia artística en la Maison des Auteurs de la ciudad de Angoulême junto al dibujante Lucas Varela para llevar a cabo el libro experimental Diagnósticos, publicado por la editorial Tanibis. Desde 2005 hasta la fecha se dedica también a la docencia tanto en la Universidad de Palermo como en forma particular.

"El cómic es el encanto espectral de esos muñecos de papel, inmóviles como marionetas sin hilos, y resulta incompatible con el cine, que tiene su seducción en el movimiento, en el ritmo, en la dinámica. Es una forma esencialmente diferente de atraer la mirada, un estilo distinto, otro modo de expresarse. El mundo del cómic podrá prestar generosamente al cine sus escenografías, personajes e historias, pero no su atractivo más secreto e inefable, que es el de la fijeza, la inmovilidad de las mariposas clavadas con un alfiler". Federico Fellini Prólogo de Viaje a Tulum, junto a Milo Manara.

Desde que los primeros analistas enfocaron sus microscopios semióticos hacia los cuadritos de historieta, la naturaleza del lenguaje (o sistema) secuencial logró escabullirse de sus mejores esfuerzos para asirlo. Muchos de los que mejor se acercaron al núcleo de la cuestión, no por casualidad, fueron los autores devenidos analistas de su propio medio de expresión. Durante décadas dos libros indispensables permanecían casi como únicos referentes: El Arte Secuencial de Will Eisner y Entendiendo el Cómic de Scott McCloud. Este último, sobre todo, pasó a ser el manual de uso cotidiano para la mayoría de los profesores de dibujo e historieta. Si para la anatomía o el dibujo natural en general estaba Loomis, para la secuenciación estaba Scott McCloud y su relectura ampliada de la teoría iniciada 
por Will Eisner. Una teoría que encontraba su base en un simple y extendido fenómeno secuencial: en la historieta, el tiempo se traduce en espacio. Los minutos, los segundos, los siglos, las tardes lentas, los viajes grises, todo es convertible en su codificación habitual de cuadritos, centímetros cuadrados, páginas.

El término clave en el que Scott Mc Cloud ancla gran parte de su teoría es "closure", habitualmente traducido como "clausura", en tanto "cierre del sentido". No es casual. Para los autores, dibujantes y guionistas, lograr la "clausura" de sus secuencias, equivale a que se entienda, o no, la historia que pretende contar. Como profesor de guión y narrativa secuencial, sé muy bien que es el principal escollo al momento de transmitir las sutilezas de la secuenciación. Es muy habitual, incluso entre profesionales, que la clausura sea completamente evidente, sólo para el autor, dejando de ese modo al lector perdido entre escenarios sin fijar, izquierdas y derechas cambiantes, interiores y exteriores indiscernibles uno del otro.

Mc Cloud clasifica seis tipos de transiciones entre cuadritos, donde la clausura debe producirse de alguna forma:

- Transición 1: momento a momento

- Transición 2: acción a acción

- Transición 3: tema a tema

- Transición 4: escena a escena

- Transición 5: aspecto a aspecto

- Transición 6: non sequitur

Casi todas las transiciones de McCloud se diferencian por el tipo de elipsis que se produce entre un cuadrito y otro. En el "aspecto a aspecto", no hay elipsis, solo movimiento espacial. En "momento a momento", el tiempo pasa en su mínima expresión. En "escena a escena", la elipsis puede ser temporal y/o contemplar un desplazamiento espacial. La transición de tema a tema, el traslado espacial también está involucrado al momento de establecer la clausura: es un mismo hecho, narrado desde dos espacios distintos. Pero es la sexta la que siempre, como profesor, me pareció insuficiente, tramposa, trampa que el mismo Mc Cloud denunciaba: el non sequitur básicamente, no existe. Siempre nuestra percepción buscará encontrar un tipo de clausura, así las dos imágenes no contengan ningún tipo de relación necesaria. Non Sequitur no es más que un continente por descarte, donde caerán todas las transiciones que no cumplan con las condiciones de las cinco categorías anteriores.

Thierry Groensteen desde su propuesta en Systéme de la bande dessinée, se da el lujo doble de no citar a Scott McCloud y al mismo tiempo desdecirlo en tanto la secuencia entre cuadritos es, para su perspectiva, solo una de la posibilidades secuenciales, las cuales va a dividir en "planos": en plano del sintagma, de la secuencia, de la serie y de la página. Básicamente, la primera viñeta de la página 4, puede establecer un fenómeno de clausura con la quinta viñeta de la página 78. O con cualquier otra, o con la página como un entero, o, estirando las posibilidades, con la imagen de la contratapa. A este fenómeno, antes que clausura, Groensteen prefiere denominarlo con el neologismo de "artrología". Tiene razón y mucha. Los autores lo sabemos bien, cada vez que relacionamos viñetas distantes entre 
sí, ya sea a través de repeticiones, ecos, citas internas, retruques y muchas otras posibilidades gráficas y textuales.

$\mathrm{Al}$ momento de tener que transmitir a mis alumnos todas las posibilidades de las relaciones entre viñetas, ya sea que estén yuxtapuestas o distanciadas en la serie lineal, mi principal inquietud, como ya dije, es que puedan operar con la paleta más extensa de recursos en pos de lograr la tan esquiva clausura. Y es ahí donde estas dos teorías, McCloud y Groensteen, resultan una buena base, pero insuficientes. Es por eso que me vi obligado a desarrollar una categorización de las diferentes formas de clausura. Tal vez por una excesiva prudencia, preferí no incurrir en neologismos y hablar, entonces, de Articulaciones Secuenciales.

\section{Articulación espacial}

Este tipo de articulación es la que está parcialmente cubierta por las categorías de McCloud. En la articulación espacial, el objetivo es lograr que se entienda cualquier movimiento en el espacio, ya sea de los personajes, objetos o el punto de vista (también mal nominado con la metáfora de "cámara"). De este modo, la articulación entre viñetas puede entenderse como adverbios de lugar, que si bien pueden aparecer como cartuchos de voz en off textuales, siempre es mejor que la clausura se produzca gráficamente, con el poder pleno del dibujo:

\section{Contextualización:}

Descubrimiento, por apertura del plano, del contexto que completa una escena. Es un recurso habitual para iniciar una escena sin hacer el recurso más habitual del plano general.

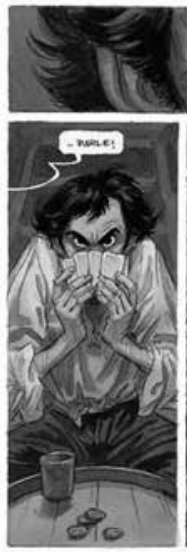

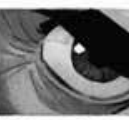

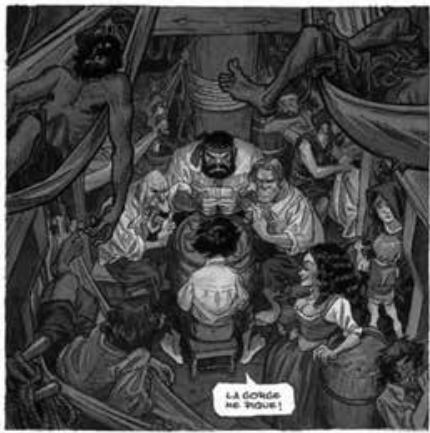

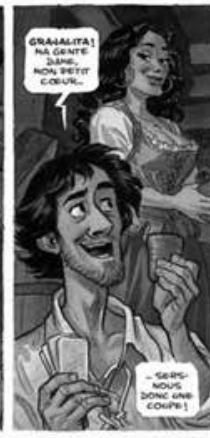

Figura 1. Les Indes Fourbes. Ayroles / Guarnido. 
De escenario interior a exterior
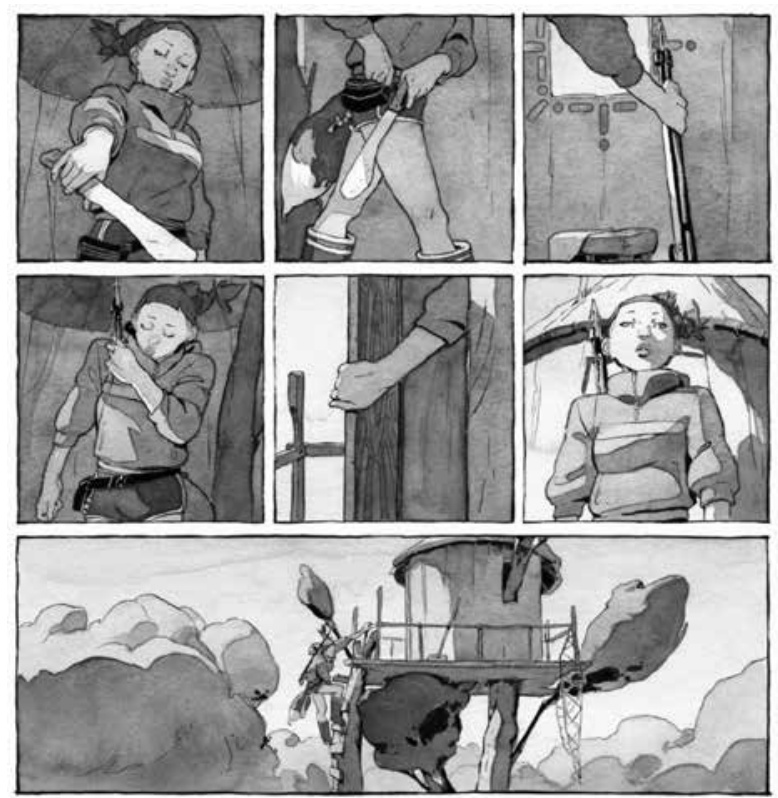

Figura 2. $L a$

Mecanique Celeste I

Merwan.

Mismo espacio (aspecto a aspecto de McCloud)

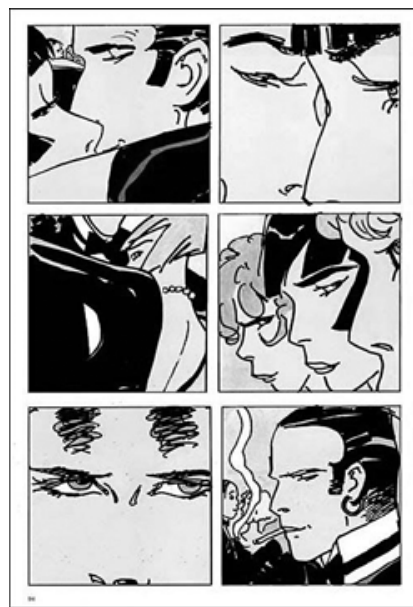

Figura 3. Tango $y$

todo a media luz I

Hugo Pratt. 


\section{Ubicación / Arriba / Abajo}

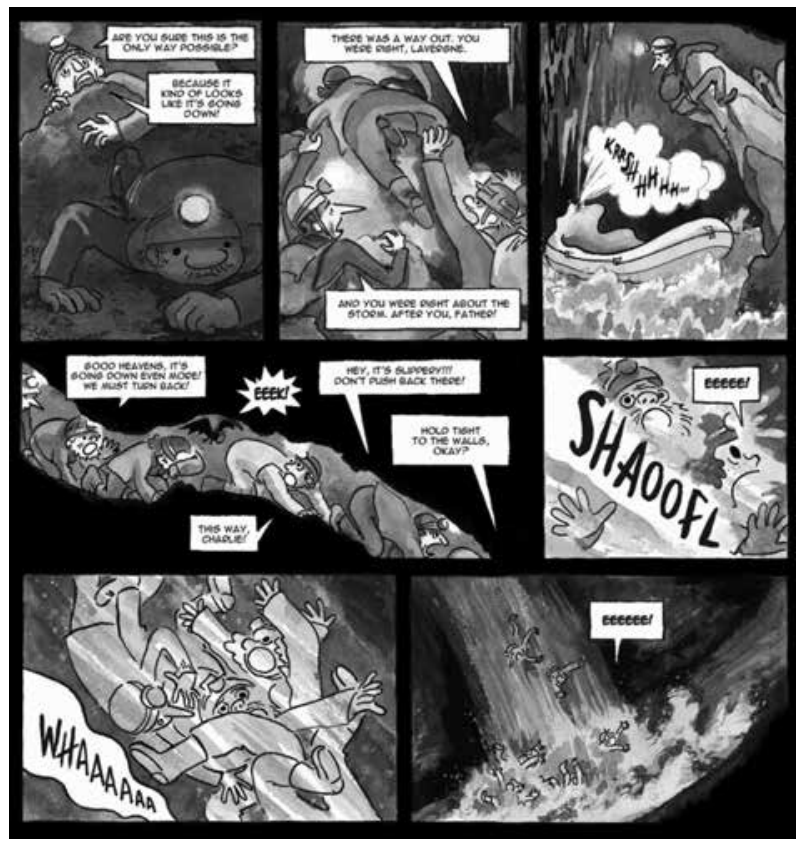

Figura 4. Satanie.

Vehlmann /

Keraskoet.

Y del mismo modo, todo otro adverbio de lugar es posible de ser traducido a una clausura gráfica: DENTRO, FUERA, ARRIBA, ABAJO, ETC. Pero lo que en texto es extremadamente fácil de lograr, para que se produzca la clausura gráfica, necesitará de encuadres específicos y de una destreza en el dibujo suficiente como para identificar espacios, objetos y personajes. Esa destreza también puede ser de diversa índole, a veces será enteramente figurativa y academicista, atenta a las leyes de fuga y perspectiva, otras será pura resolución estilística, las hermosas mentiras gráficas que los dibujantes vienen cultivando desde la era industrial.

\section{Articulación temporal}

Los adverbios temporales, en su traducción gráfica, son el blanco preferido de Scott McCloud. Otra vez, como sucede con la articulación espacial, las categorías de McCloud son inespecíficas. Es por eso que prefiero ir adverbio por adverbio y en ese ejercicio, tratar de encontrar los recursos más legítimos y/o originales. 


\section{Un segundo después}

Es una de las clausuras más habituales y la base de la secuenciación. Es la equivalente al momento a momento de Mc Cloud.
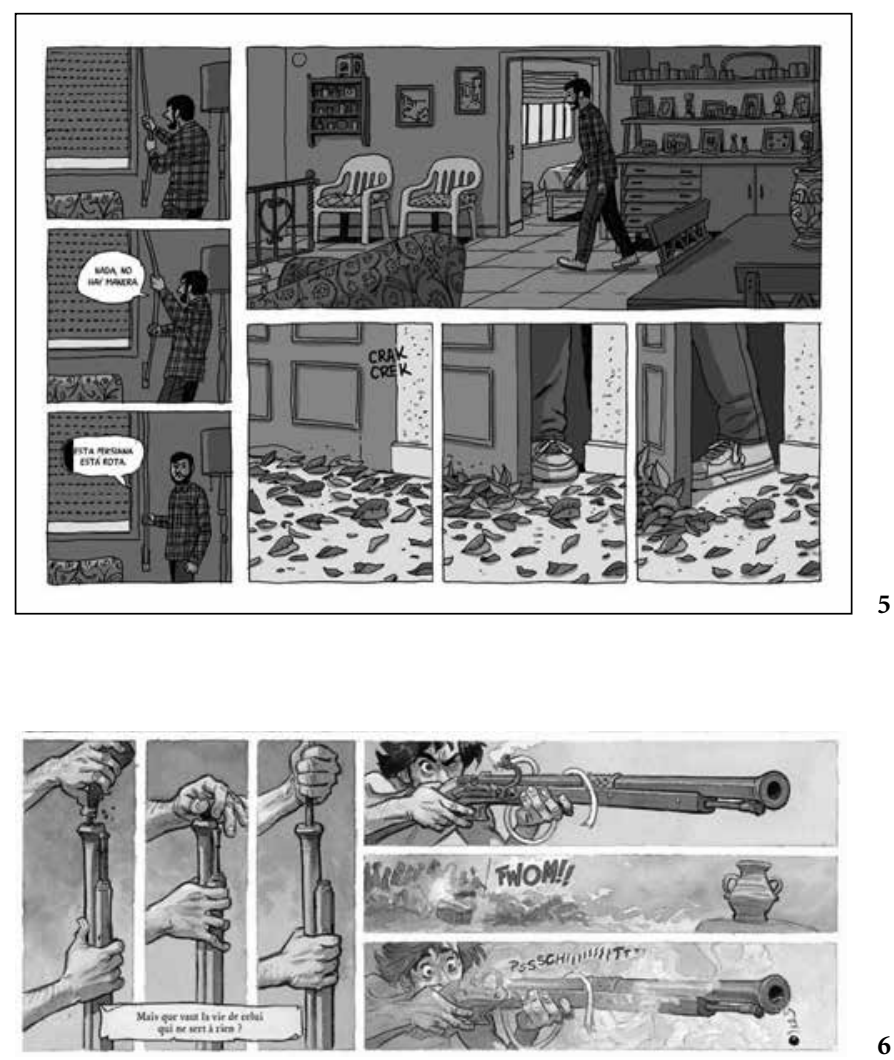

Figura 5. La Casa / Paco Roca. Figura 6. Les Indes Fourbes. Ayroles / Guarnido. 


\section{Flashback / Recuerdo / Crónica del Pasado:}
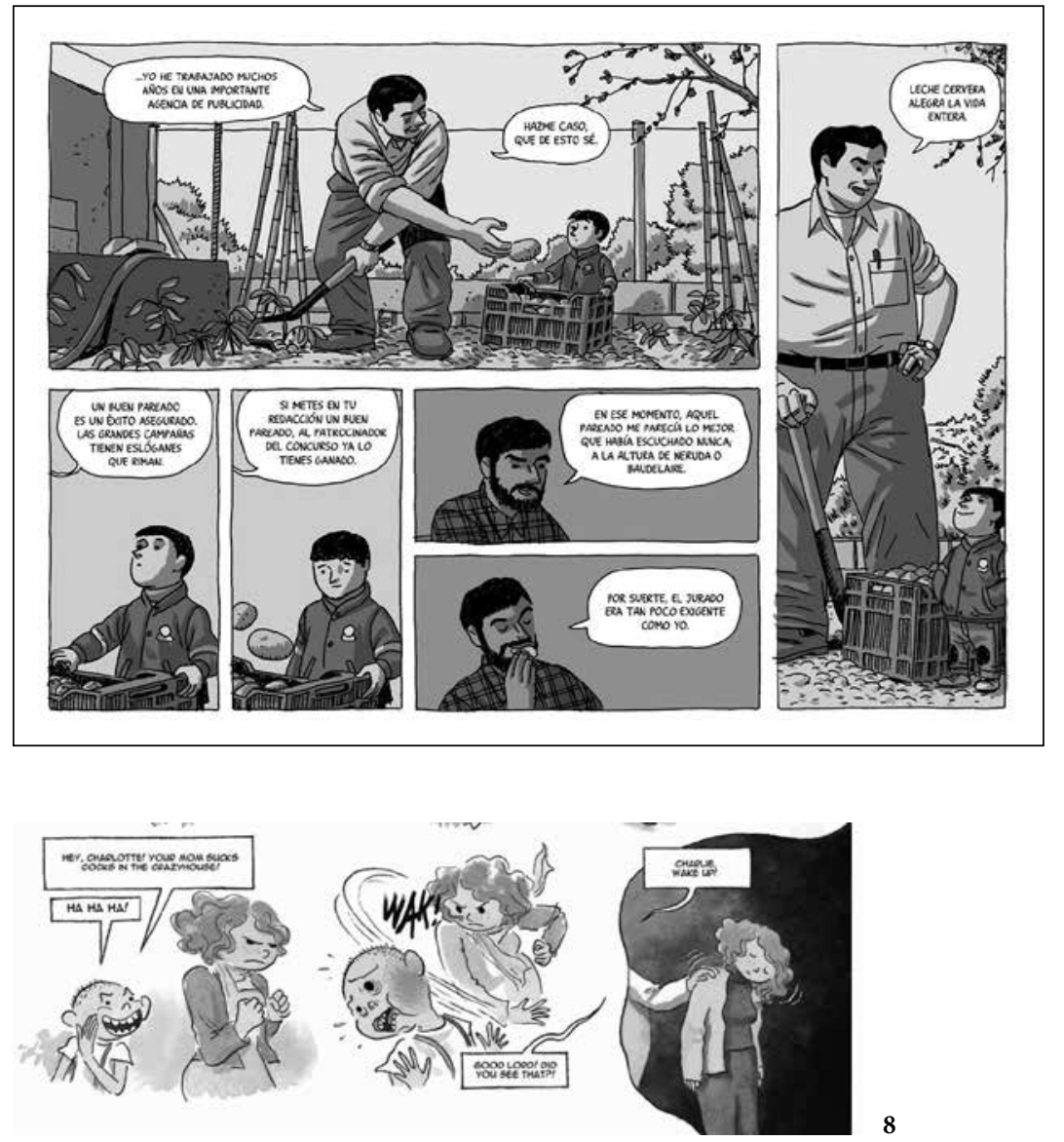

Figura 7. La Casa / Paco Roca. Figura 8. Satanie. Vehlmann / Keraskoet.

Para provocar la clausura de tiempos pretéritos valiéndose solamente de recursos gráficos se han sistematizado ciertos códigos gráficos típicos, algunos cromáticos: sepias, grises, otros de técnica: terminación a lápiz, sin entintar, doble entintado, etc. Pero los más legítimos, y desafiantes, son los que no recurren a ningún tipo de artilugio técnico y que se abastecen para generar clausura con los encuadres y planos puros, sin tampoco acudir a las leyendas típicas en voz en off: "Años antes", "un mes atrás", "previamente”, etc. Este tipo de articulaciones temporales hacia el pasado, no existen en la clasificación de McCloud. 


\section{Antes:}

Un desafío de la articulación temporal aparece cuando la clausura demanda que el lector clausure que el cuadro siguiente representa un hecho anterior inmediato, es decir, un hecho previo recient. Es un tipo de clausura familiar, pero distinta, al "flashback".

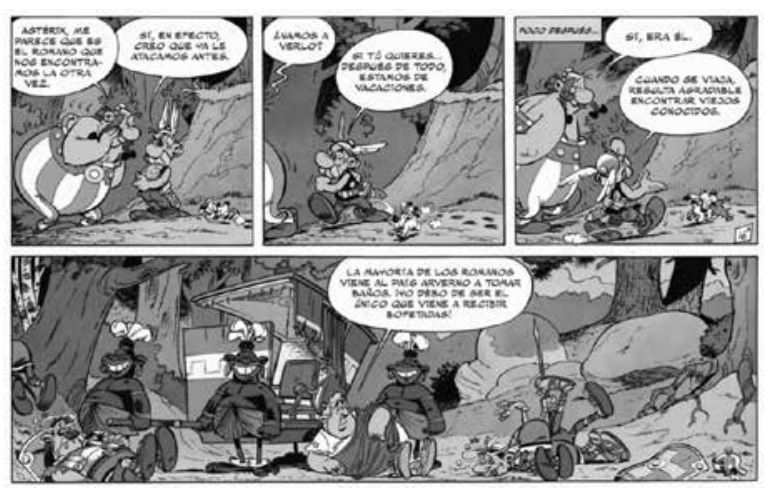

Figura 9. Asterix. Goscinny / Uderzo.

\section{A la mañana siguiente / al otro día}

La articulación necesaria para dar a entender una elipsis que llega hasta el siguiente, muchas veces presenta problemas de clausura y se termina recurriendo a la apoyatura textual, en voz en off "al otro día" o parecidos. En la historieta moderna, se prescinde de las aclaraciones textuales, al recurrir a una combinatoria de cambio de página (especialmente de impar a par), plano general y muchas veces, vista del sol amaneciendo.
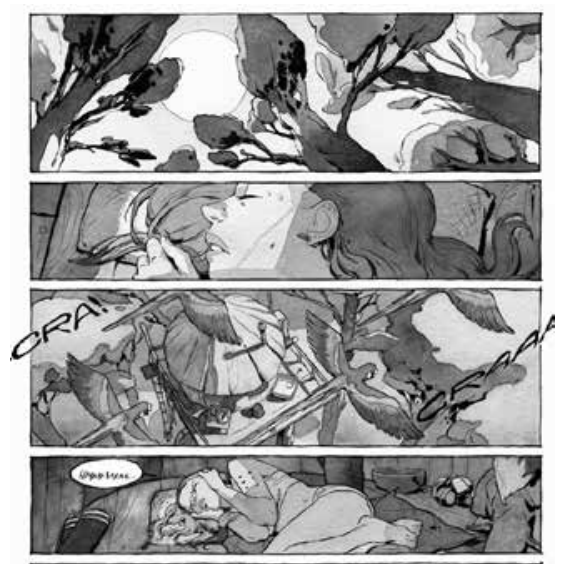

Figura 10. El sol sale, la chica despierta con el ruido de los papagayos, a al MAÑANA siguiente. La Mecanique Celeste / Merwan. 


\section{Resumen / Racconto:}

Hechos distanciados en el tiempo, que resumen a través de elipsis medianas un lapso prolongado. Es el equivalente de las transiciones de tipo escena a escena de McCloud. Este tipo de articulación suele estar apoyado, aunque no siempre, con textos narrativos.

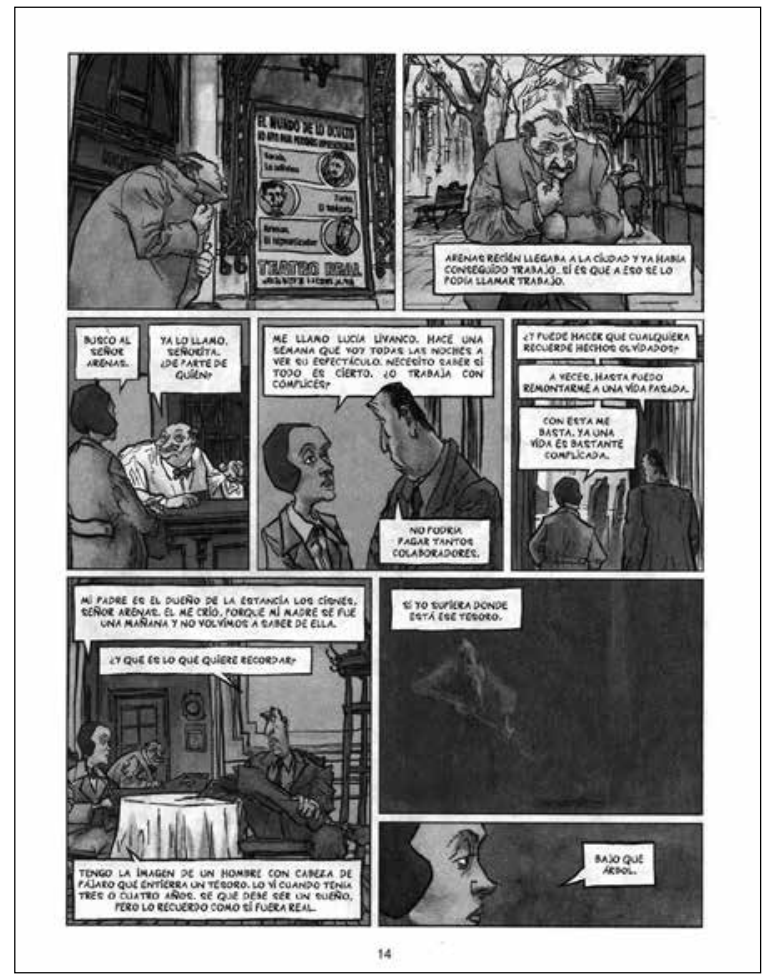

Figura 11. El

Hipnotizador. Pablo

De Santis / Juan

Saenz Valiente.

\section{Articulación semántica}

Este tipo de articulaciones no existe en las clasificaciones de McCloud, salvo tal vez, dentro de "tema a tema" o "acción a acción", pero otra vez, sin especificar el tipo de relación entre las dos viñetas. En la articulación semántica, el desafío es lograr en el lector un tipo de concatenación lógica. Si en las articulaciones temporal y espacial, los equivalentes eran adverbios de tiempo y espacio, en la articulación semántica los equivalentes son los nexos de diverso tipo: 


\section{Consecutivos: por lo tanto / por consiguiente}

Relación causa-efecto. La viñeta primera es causa directa de la segunda. La articulación semántica de este tipo, necesita de una clausura temporal previa, ya que un hecho antecede temporalmente al otro. La articulación temporal es condición necesaria, pero no suficiente, ya que también debe clausurarse la relación lógica entre los hechos.
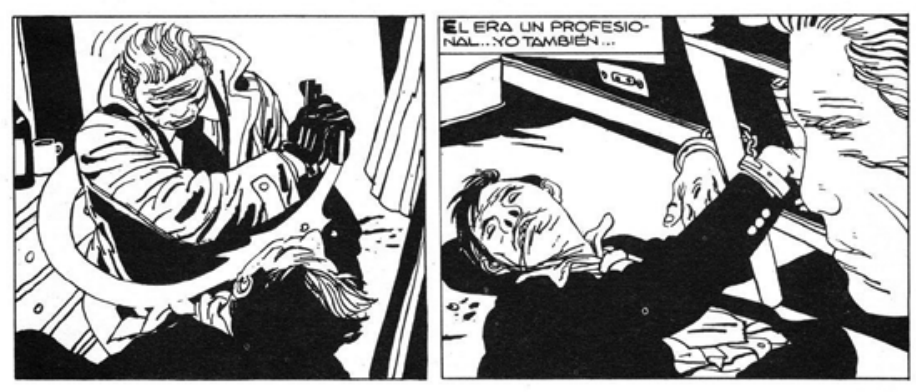

Figura 12. Alack Sinner / Muñoz y Sampayo.

\section{Causales: porque / puesto que}

Relación efecto-causa. La viñeta primera presenta el hecho consumado, mientras en la segunda presenta la causa próxima anterior.

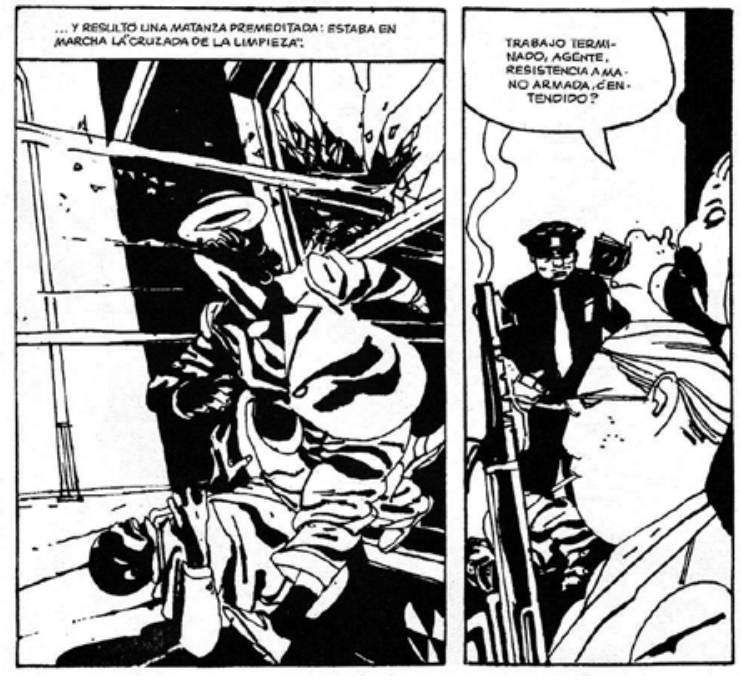

Figura 13. Alack

Sinner. Muñoz y Sampayo. Los personajes murieron acribillados (consecuencia primero) PUESTO QUE los mafiosos arreglaron con la policía (causa segundo). 


\section{Adversativos: sin embargo / pero}

Relativización del sentido de un hecho.

13
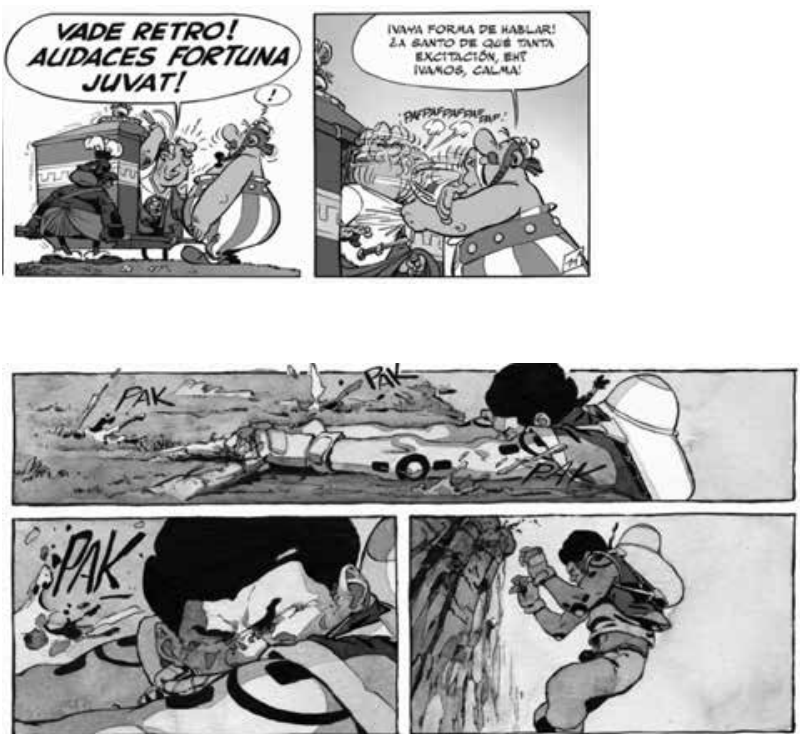

14

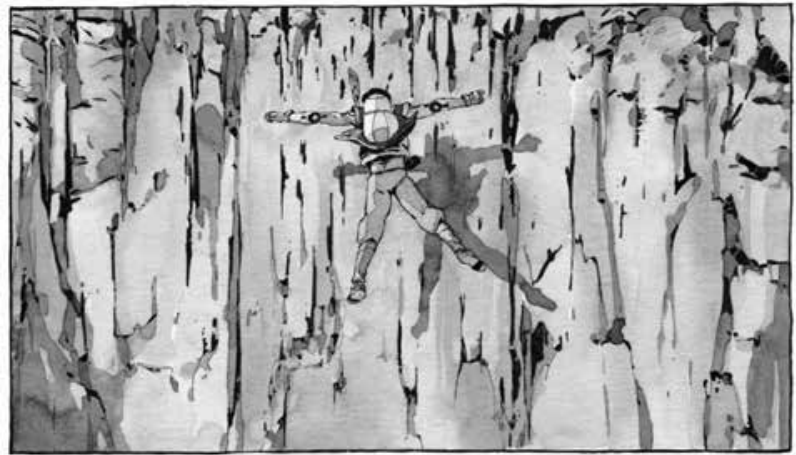

Figura 13. "El romano pretende imponer su autoridad PERO Obélix lo sopapea”. Asterix / Goscinny / Uderzo. Figura 14. La Mecanique. Celeste. Merwan. "El personaje logra asirse de uan raíz, PERO la misma se rompe: PAK”. 


\section{Copulativos: también / incluso / además}

Sumatoria de hechos de la misma índole, donde la repetición genera la necesidad de una clausura propia.
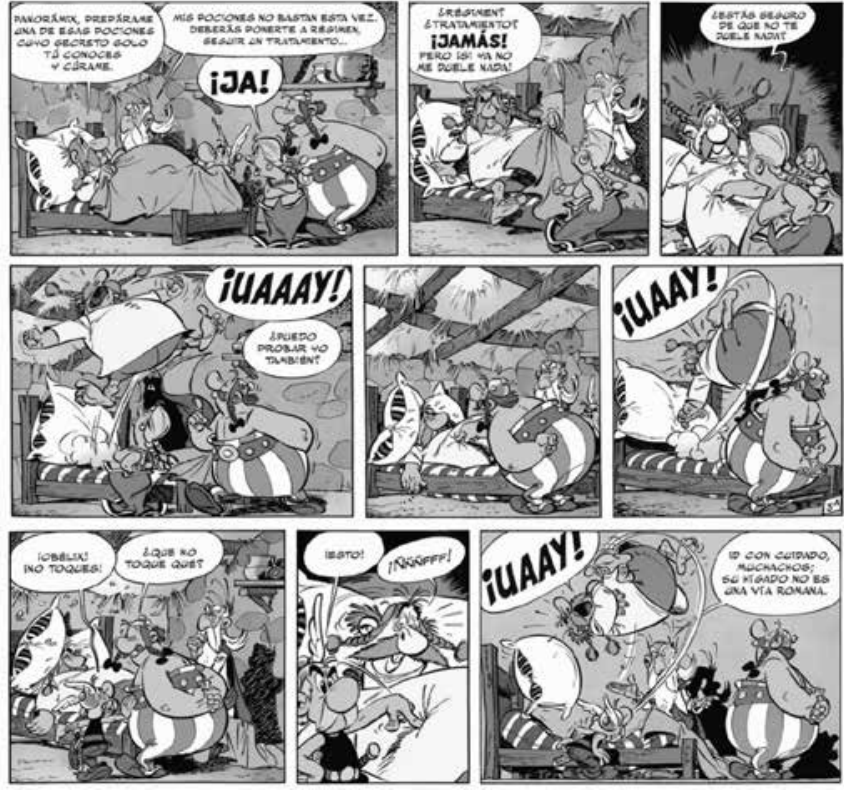

Figura 16.

"Clarabella le toca el hígado adolorido a Abraracurcix, TAMBIÉN Obélix, TAMBIÉN Astérix". Asterix / Goscinny / Uderzo.

\section{Exclusión: por el contrario / en cambio}

Contraste de un hecho con otro de signo invertido.
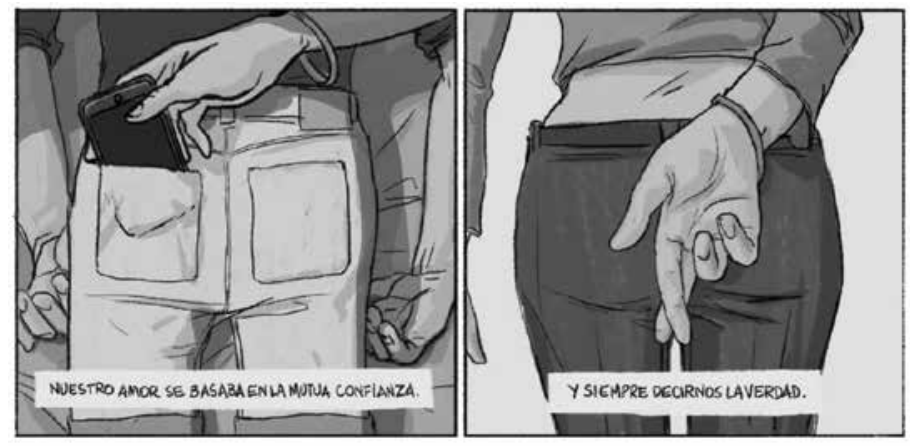

Figura 17. Verla.

Agrimbau / Ginevra. 


\section{Articulación retórica}

En la articulación de tipo retórica, la clausura no solo es espacio-temporal, sino que requiere otro tipo de decodificación no literal. Muchas de las figuras retóricas se aplican a nivel gráfico en este tipo de clausuras. También pueden equipararse a los conectores comparativos: como si, de modo tal, igualmente, de forma análoga, etc.

\section{Metáfora en sintagma}

La manzana metaforiza a la chica (she), así como el estado de la mente del muchacho robot. Es "en sintagma", porque se vale de un objeto dentro de la diégesis, presente en la escena: la manzana que atraviesa la mano del chico. Metáfora en Sintagma es término de Christian Metz, en Psicoanálisis y Cine.
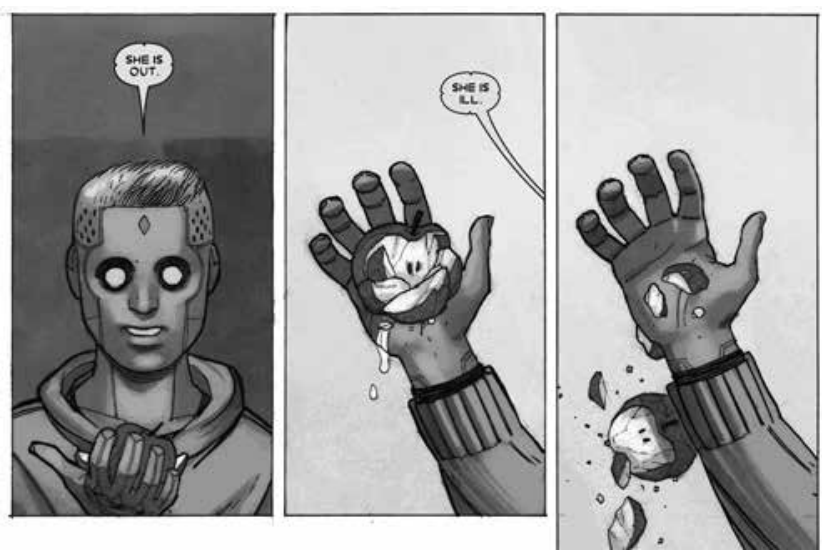

Figura 18. The Vision - Tom King / Gabriel Hernández.

\section{Metáfora en paradigma}

La comparación o imagen símil no pertenece al mundo diegético. Se yuxtapone apelando a un tipo de clausura no literal, para provocar un sentido estético o emocional, muchas veces, ambiguo. Es el tipo de clausura que suele interpretarse como (o reducirse a) onírica y/o alucinatoria. Scott McCloud prevee en una aclaración a su transición Non-Sequitur, que siempre se produce algún tipo de clausura, sin importar cuáles son las dos imágenes yuxtapuestas. Dentro de la articulación retórica, y especialmente en la metáfora paradigmática, pueden englobarse muchas de las transiciones que él llama "non-sequitur". Metáfora en Paradigma es término de Christian Metz, en Psicoanálisis y Cine. 

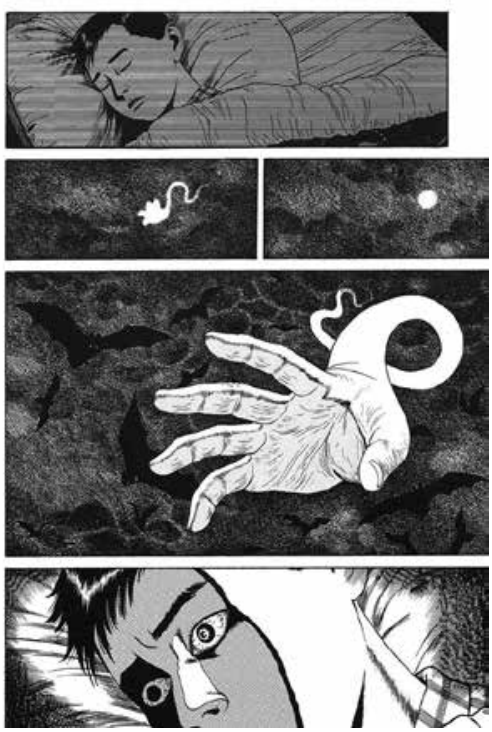

19
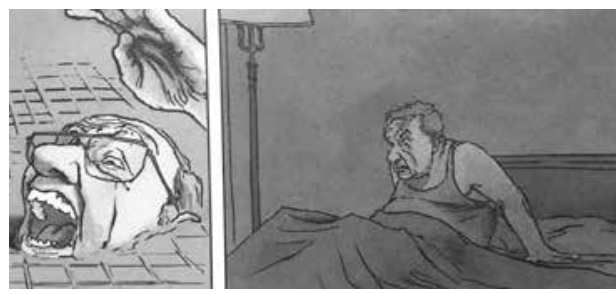

20

Figura 19. Uzumaki. Junji Ito.

Figura 20. La Sudestada. Juan

Sáenz Valiente.

\section{Hipérbole}

En la hipérbole gráfica, los rasgos se acentúan y exageran sin que ello implique un cambio literal en la fisonomía del personaje. La clausura requerida implica no interpretar un cambio literal en el personaje, sino una representación de un sentimiento, estado de ánimo o sensación.

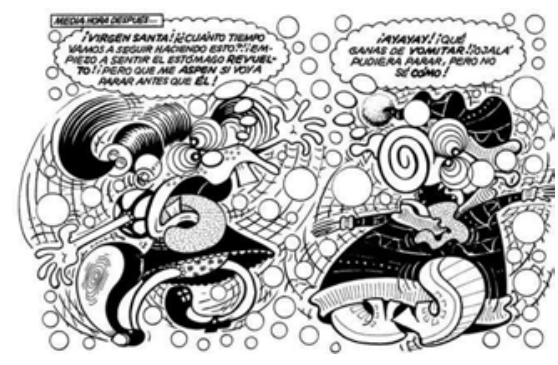

Figura 21. Girly-Girl / Peter Bagge.

Las hiperboles también pueden ser de un tipo muy distinto. Si en la anterior la clausura demandada es hiperbólica y caricaturesca, la siguiente combina la hiperbole de tamaño con metáfora en sintagma, en busca de un efecto no literal, retórico: 


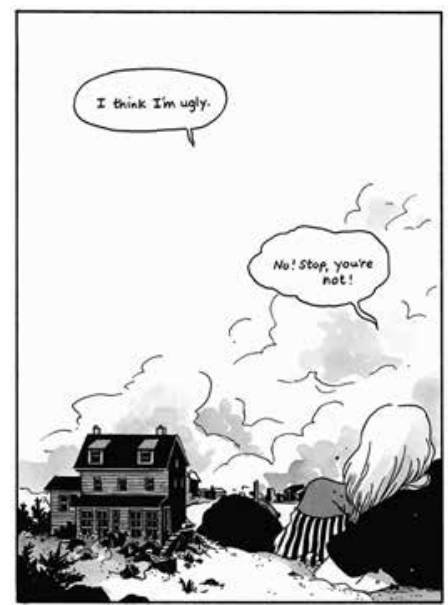

Figura 22. I Love this Part. Tilie Walde.

\section{Ironía}

La ironía gráfica se produce cuando el contenido de un cuadro debe interpretarse de forma contraria a la literal. En el ejemplo, en el último cuadro, el gesto sonriente y el "yes" han dejado de ser literales para ser irónicos, connotando la negación de la autora ante la angustiosa cercanía de su cumpleaños $\mathrm{N}^{\circ} 30$. Asimismo se sirve de una metáfora sintagmática al transformar al cumpleaños Nro 30 en un personaje antropomorfo.

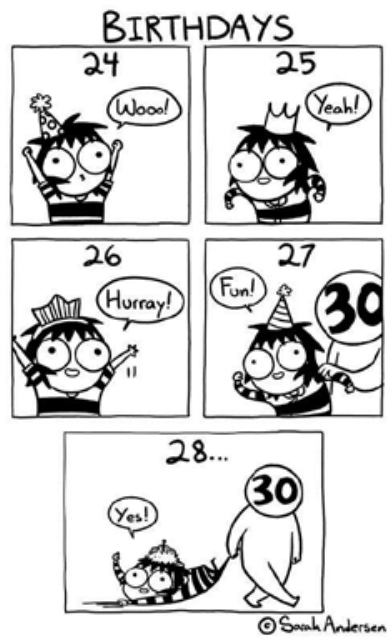

Figura 23. Sarah's Scribbles. Sarah Andersen. 


\section{Caricatura}

Muchas veces un personaje cambia sus características anatómicas para resaltar el efecto de sentido deseado de una situación. En el manga japonés suele llamarse "chibi" a la versión de personajes miniaturizados y aniñados. Es una de las formas posibles de la caricatura. Nuevamente, la clausura no es literal, el lector no entiende que el personaje se achicó, sino que interpreta que está avergonzado, asustado o está asumiendo una actitud infantil.

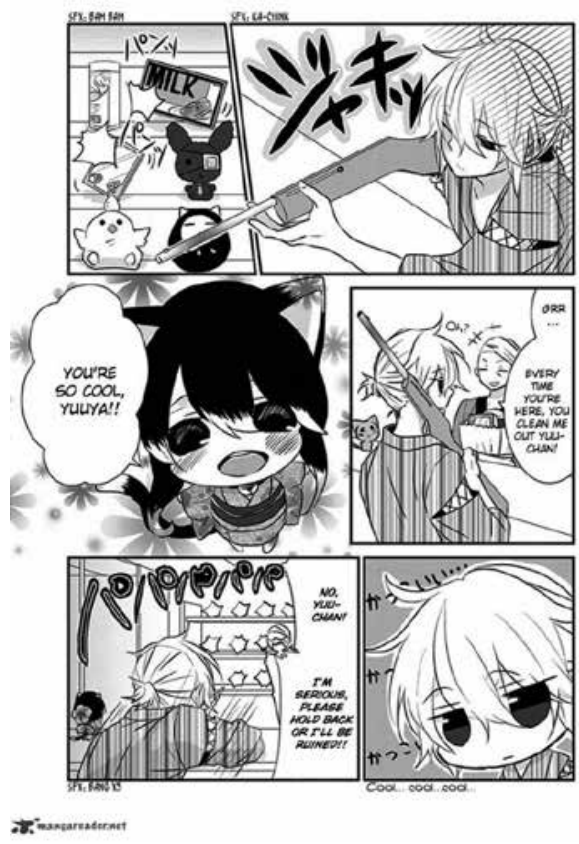

Figura 24. Nukoduke. Yugi.

\section{Idealización}

Como una forma inversa de la caricatura, la idealización opera de la misma forma pero en sentido contrario: las características del personaje se idealizan, sus proporciones cambian. Muchas veces se vuelve más realista, el estilo y la técnica abandonan lo icónico y se acerca al estilo fotográfico.

El personaje del ejemplo, One Punch Man, suele permanecer en su estado icónico durante la mayor parte de la historia, pero cuando entra en batalla, su estilo cambia y a través de la idealización, adquiere un estilo épico y más anatómicamente realista. Este efecto no deja de tener un matiz irónico. 

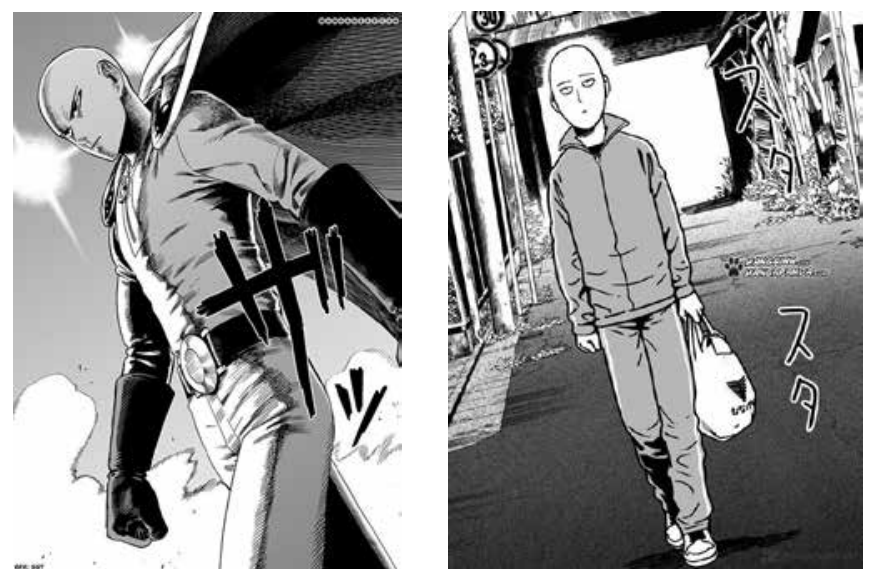

Figura 25. One Punch Man. One.

\section{Sinécdoque}

La parte por el todo, es un recurso inevitable y natural de la composición, tanto primeros planos como en planos detalle, donde la clausura natural es entender que aunque veamos solamente la cabeza, se trata solamente de una vista parcial de una persona completa. Otras calusuras sinecdóquicas se producen cuando "la parte" del "todo" en vez de ser una sección del cuerpo, son sus proyecciones, sus sombras, sus siluetas.

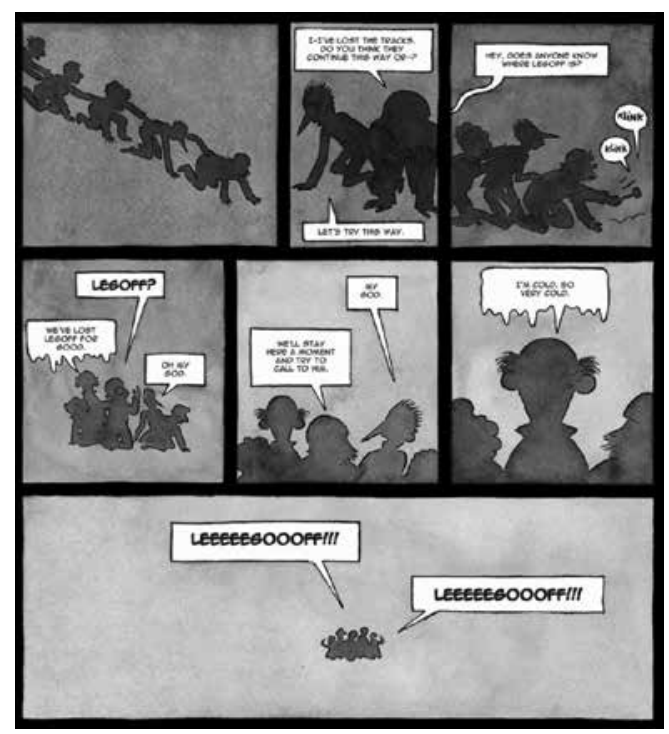

Figura 26. Satanie.

Vehlmann /

Keraskoet. 


\section{Metonimia}

$\mathrm{Al}$ igual que sucede con la sinécdoque, las metonimias gráficas recurren al reemplazo por objetos, armas o vestimentas de los personajes, para dar cuenta de su presencia y ubicación.
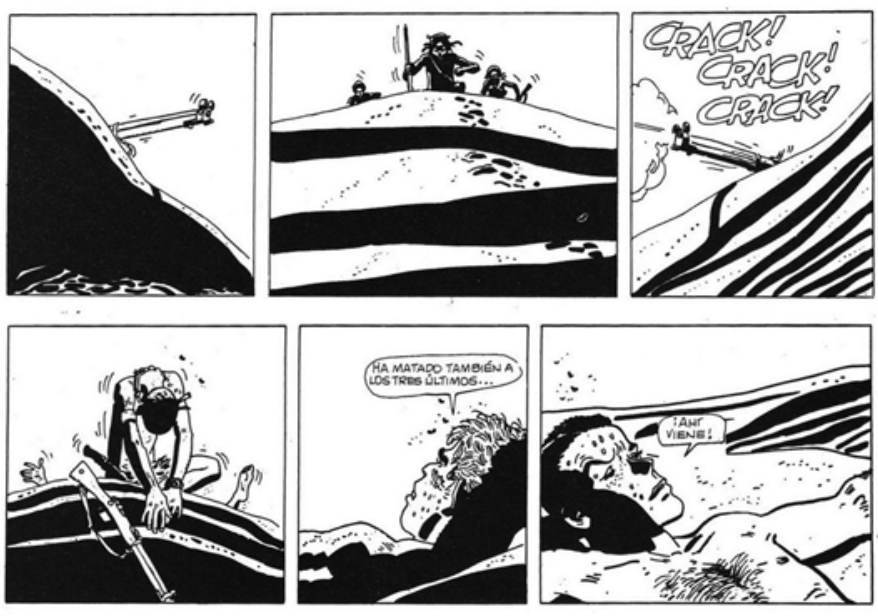

Figura 27. Los

Escorpiones del

Desierto. Hugo Prat.

\section{Conclusiones}

La diversidad del tipo de articulaciones es también un índice de un mayor dominio del lenguaje secuencial por parte de los autores, guionistas y dibujantes, en el momento de ser capaces de generar diferentes clausuras, sentidos de lectura, al contar una historia en imágenes. Muchas veces el desafío de los profesores de dibujo y guion es dotar de recursos de clausura a sus alumnos, cuando invariablemente el problema más común entre los historietistas principiantes es que las secuencias no se entiendan, es decir, no produzcan la clausura que intentaron lograr.

Los fenómenos de creación de sentido entre viñetas, la clausura del sentido, son muchos más complejos y diversos que lo que se puede deducir en función de las categorías existentes tanto en Groensteen o McCloud. El desarrollo y un rastreo más extenso del universo de posibles clausuras entre viñetas, más allá de los espacio temporal, requiere de una investigación mucho más vasta que las intenciones y posibilidades de este artículo, que espero pueda servir como iniciador de un relevo más amplio.

Este elevo debe incluir a todos los tipos de historieta: tiras cómicas, manga japonés, álbumes francobegas, comic books norteamericanos, historieta sudamericana, on line, webtoons, etc. Otro tema pendiente es evaluar como cambian los tipos de clausuras según la procedencia cultural de las historietas, como así también, que elementos se mantienen 
siempre estables, como piedras fundamentales del sistema secuencial gráfico, que podría considerarse un verdadero lenguaje universal. 